\title{
Pacific
}

Journal of

Mathematics

\section{MINIMAL SETS OF A RECURRENT DISCRETE FLOW}

HATTAв HaWETE 


\title{
MINIMAL SETS OF A RECURRENT DISCRETE FLOW
}

\author{
HATTAB HAWETE
}

\section{S. G. Dani, giving a counterexample to a result in a paper of Knight, showed that recurrent transitive flows can admit multiple minimal sets. Here we show that such a phenomenon occurs on a wider scale.}

Let $(X, T)$ be a discrete flow, where $X$ is a compact metric space and $T$ is a self-homeomorphism of $X$. For $x \in X$, the set $\left\{T^{n}(x): n \in \mathbb{Z}\right\}$ is called the orbit of $x$ and is denoted by $O(x, T)$. A set $W$ is a minimal set of $(X, T)$ if for all $x \in W$ we have $\overline{O(x, T)}=W$. The study of minimal sets of such a system is a central question in topological dynamics. Zorn's lemma ensures the existence of at least a minimal set of $(X, T)$. If $X$ is a minimal set, $(X, T)$ is called a minimal flow.

A point $x$ of $X$ is recurrent if $T^{n_{k}}(x) \rightarrow x$ for some sequence $n_{k} \rightarrow+\infty$. When each point of $X$ is recurrent we say that $(X, T)$ is a recurrent flow. All periodic points are recurrent. The standard example of a nonperiodic recurrent point is any point in the irrational flow on the circle $\mathbb{S}^{1}$. Every point in a minimal set is recurrent, so the existence of minimal sets implies the existence of recurrent points.

Knight [1987] purported to prove that, if $X$ is a compact recurrent orbit closure in $(X, T)$, then any pair of orbit closures intersect and, in particular, $X$ contains a unique compact minimal set. Dani [1991] pointed out with a counterexample that this statement is false.

In Theorem 0.1 below we enlarge the class of known counterexamples. More specifically, for any weakly mixing, minimal, uniformly rigid system $(X, T)$ the system $(X \times X, T \times T)$, defined by $(T \times T)\left(x_{1}, x_{2}\right)=\left(T\left(x_{1}\right), T\left(x_{2}\right)\right)$ for $\left(x_{1}, x_{2}\right) \in$ $X \times X$, is a recurrent and transitive system with multiple minimal sets.

(Recall that the a discrete flow $(X, T)$ is called

- transitive if there exists $x_{0} \in X$ with a dense orbit;

- ergodic if for all two open subsets $U$ and $V$ there exits $n$ such that $T^{n} U \cap V$ is nonempty;

- weakly mixing if the discrete flow $(X \times X, T \times T)$ is ergodic;

MSC2010: 54H20.

Keywords: minimal set, discrete flow, uniformly rigid, weakly mixing. 
- uniformly rigid if there exists a sequence $n_{k} \rightarrow+\infty$ such that

$$
\lim _{n_{k} \rightarrow+\infty} \sup _{x \in X} d\left(T^{n_{k}} x ; x\right)=0,
$$

where $d$ is the metric on $X$.)

Minimal uniformly rigid weakly mixing systems exist; see [Glasner and Maon 1989, Proposition 6.5].

Theorem 0.1. Let $(X, T)$ be a minimal uniformly rigid weakly mixing system. Then $(X \times X, T \times T)$ is transitive and recurrent, and admits infinitely many minimal sets.

Proof. Let $(X, T)$ be a minimal uniformly rigid weakly mixing system.

Step 1: $(X \times X, T \times T)$ is transitive. Since $(X, T)$ is weakly mixing, $(X \times X, T \times T)$ is ergodic. But for discrete flows on compact spaces, ergodicity is equivalent to transitiveness; see [de Vries 1993], for example. Because $X \times X$ is compact, this means that $(X \times X, T \times T)$ is transitive.

Step 2: $(X \times X, T \times T)$ is recurrent. Since $(X, T)$ is a uniformly rigid flow, there is a sequence $n_{k} \rightarrow+\infty$ such that

$$
\lim _{n_{k} \rightarrow+\infty} \sup _{x \in X} d\left(T^{n_{k}} x, x\right)=0 .
$$

For each point $(x, y)$ point of $X \times X$ we have

$$
\lim _{n_{k} \rightarrow+\infty}(T \times T)^{n_{k}}(x, y)=\lim _{n_{k} \rightarrow+\infty}\left(T^{n_{k}} x, T^{n_{k}} y\right)=(x, y) .
$$

Thus $(x, y)$ is a recurrent point and so $(X \times X, T \times T)$ is a recurrent discrete flow. Step 3: There are infinitely many minimal sets of $(X \times X, T \times T)$. Define $D_{n}=$ $\left\{\left(x, T^{n}(x)\right): x \in X\right\}$. Then $D_{n}$ is an invariant closed set of $(X \times X, T \times T)$. If $F$ is a nonempty closed $(T \times T)$-invariant subset of $D_{n}$, then so is its projection, say $p_{1}(F)$, on the first factor. By the minimality of $T$ we get $p_{1}(F)=X$, and hence $F=D_{n}$. Thus $D_{n}$ is minimal for every $n$. Since $(X, T)$ is minimal it follows that the $D_{n}$ are pairwise distinct.

Remark 0.2. The discrete flow $(X \times X, T \times T)$ does not have fixed points because we chose $(X, T)$ as a minimal discrete flow.

\section{Acknowledgement}

The author gratefully acknowledges helpful corrections, comments and suggestions from the referee. 


\section{References}

[Dani 1991] S. G. Dani, "A remark on recurrent dynamical systems", J. Indian Math. Soc. (N.S.) 56:1-4 (1991), 1-6. MR 93g:58113 Zbl 0864.54033

[Glasner and Maon 1989] S. Glasner and D. Maon, "Rigidity in topological dynamics", Ergodic Theory Dynam. Systems 9:2 (1989), 309-320. MR 90h:54050 Zbl 0661.58027

[Knight 1987] R. A. Knight, "Minimal sets in recurrent discrete flows", Proc. Amer. Math. Soc. 100:1 (1987), 195-198. MR 88f:54076 Zbl 0612.54051

[de Vries 1993] J. de Vries, Elements of topological dynamics, Math. and its Appl. 257, Kluwer, Dordrecht, 1993. MR 94m:54098 Zbl 0783.54035

Received February 19, 2010. Revised June 14, 2010.

HatTab HaweTE

InSTITUT SUPÉRIEUR D'INFORMATIQUe ET DU MUlTimedia

ROUTE DE TUNIS KM 10

B.P. 242

SFAX 3021

TUNISIA

hattab.hawete@yahoo.fr 


\title{
PACIFIC JOURNAL OF MATHEMATICS
}

\author{
http://www.pjmath.org \\ Founded in 1951 by
}

E. F. Beckenbach (1906-1982) and F. Wolf (1904-1989)

\section{EDITORS}

V. S. Varadarajan (Managing Editor)

Department of Mathematics

University of California

Los Angeles, CA 90095-1555

pacific@math.ucla.edu

Vyjayanthi Chari

Department of Mathematics

University of California

Riverside, CA 92521-0135

chari@math.ucr.edu

\section{Robert Finn}

Department of Mathematics Stanford University

Stanford, CA 94305-2125

finn@math.stanford.edu

Kefeng Liu

Department of Mathematics

University of California

Los Angeles, CA 90095-1555

liu@math.ucla.edu
Darren Long

Department of Mathematics

University of California

Santa Barbara, CA 93106-3080

long@math.ucsb.edu

Jiang-Hua Lu

Department of Mathematics

The University of Hong Kong

Pokfulam Rd., Hong Kong jhlu@maths.hku.hk

Alexander Merkurjev

Department of Mathematics University of California

Los Angeles, CA 90095-1555 merkurev@math.ucla.edu
Sorin Popa

Department of Mathematics

University of California

Los Angeles, CA 90095-1555

popa@math.ucla.edu

Jie Qing

Department of Mathematics

University of California

Santa Cruz, CA 95064

qing@ cats.ucsc.edu

Jonathan Rogawski

Department of Mathematics

University of California

Los Angeles, CA 90095-1555

jonr@math.ucla.edu

\section{PRODUCTION}

pacific@math.berkeley.edu

Silvio Levy, Scientific Editor Matthew Cargo, Senior Production Editor

ACADEMIA SINICA, TAIPEI

CALIFORNIA INST. OF TECHNOLOGY

INST. DE MATEMÁTICA PURA E APLICADA

KEIO UNIVERSITY

MATH. SCIENCES RESEARCH INSTITUTE

NEW MEXICO STATE UNIV.

OREGON STATE UNIV.

\section{SUPPORTING INSTITUTIONS}

STANFORD UNIVERSITY
UNIV. OF BRITISH COLUMBIA
UNIV. OF CALIFORNIA, BERKELEY
UNIV. OF CALIFORNIA, DAVIS
UNIV. OF CALIFORNIA, LOS ANGELES
UNIV. OF CALIFORNIA, RIVERSIDE
UNIV. OF CALIFORNIA, SAN DIEGO
UNIV. OF CALIF., SANTA BARBARA

UNIV. OF CALIF., SANTA CRUZ

UNIV. OF MONTANA

UNIV. OF OREGON

UNIV. OF SOUTHERN CALIFORNIA

UNIV. OF UTAH

UNIV. OF WASHINGTON

WASHINGTON STATE UNIVERSITY

These supporting institutions contribute to the cost of publication of this Journal, but they are not owners or publishers and have no responsibility for its contents or policies.

See inside back cover or www.pjmath.org for submission instructions.

The subscription price for 2011 is US \$420/year for the electronic version, and \$485/year for print and electronic.

Subscriptions, requests for back issues from the last three years and changes of subscribers address should be sent to Pacific Journal of Mathematics, P.O. Box 4163, Berkeley, CA 94704-0163, U.S.A. Prior back issues are obtainable from Periodicals Service Company, 11 Main Street, Germantown, NY 12526-5635. The Pacific Journal of Mathematics is indexed by Mathematical Reviews, Zentralblatt MATH, PASCAL CNRS Index, Referativnyi Zhurnal, Current Mathematical Publications and the Science Citation Index.

The Pacific Journal of Mathematics (ISSN 0030-8730) at the University of California, c/o Department of Mathematics, 969 Evans Hall, Berkeley, CA 94720-3840, is published monthly except July and August. Periodical rate postage paid at Berkeley, CA 94704, and additional mailing offices. POSTMASTER: send address changes to Pacific Journal of Mathematics, P.O. Box 4163, Berkeley, CA 94704-0163.

PJM peer review and production are managed by EditFLOW ${ }^{\mathrm{TM}}$ from Mathematical Sciences Publishers.

PUBLISHED BY PACIFIC JOURNAL OF MATHEMATICS

at the University of California, Berkeley 94720-3840

A NON-PROFIT CORPORATION

Typeset in IATEX

Copyright $(2011$ by Pacific Journal of Mathematics 


\section{PACIFIC JOURNAL OF MATHEMATICS}

Volume $250 \quad$ No. $2 \quad$ April 2011

Realizing profinite reduced special groups

VinCENT Astier and Hugo Mariano

On fibered commensurability

DANNy CALEGARI, Hongbin SUN and Shicheng WANG

On an overdetermined elliptic problem

LAURENT HaUswirTh, FrÉdÉRIC HÉLEIN and FranK PACARD

Minimal sets of a recurrent discrete flow

HATTAB HAWETE

Trace-positive polynomials

IGOR KLEP

Remarks on the product of harmonic forms

LiviU ORnea and Mihaela Pilca

Steinberg representation of GSp(4): Bessel models and integral representation of $L$-functions

Ameya Pitale

An integral expression of the first nontrivial one-cocycle of the space of long knots in $\mathbb{R}^{3}$

KEIICHI SAKAI

Burghelea-Haller analytic torsion for twisted de Rham complexes

GUANGXIANG SU

$K(n)$-localization of the $K(n+1)$-local $E_{n+1}$-Adams spectral sequences

TAKESHI TORII

Thompson's group is distorted in the Thompson-Stein groups

Claire Wladis

Parabolic meromorphic functions 